\title{
Menopausal Symptoms and Its Correlates: A Study on Tribe and Caste Population of East India
}

\author{
Doyel Dasgupta, Priyanka Karar, Subha Ray, and Nandini Ganguly \\ Department of Anthropology, University of Calcutta, 35 Ballygunge Circular Road, Kolkata, West Bengal 700019, India \\ Correspondence should be addressed to Doyel Dasgupta; doel.dasgupta83@gmail.com
}

Received 1 May 2015; Accepted 9 July 2015

Academic Editor: Fulvio Lauretani

Copyright (C) 2015 Doyel Dasgupta et al. This is an open access article distributed under the Creative Commons Attribution License, which permits unrestricted use, distribution, and reproduction in any medium, provided the original work is properly cited.

\begin{abstract}
Present study aimed to compare the incidence of menopausal problems and concomitants between tribe and caste population. This cross section study was conducted in five villages of West Bengal, a state in the eastern part of India. This study was conducted between two different ethnic groups-one of the "Particularly Vulnerable Tribal Groups (PTG)" of India named as "Lodha" and the other was a Bengali speaking caste population. A total number of 313 participants were finally recruited for this study. Study participants were married, had at least one child, had no major gynaecological problems, and had stopped menstrual bleeding spontaneously for at least 1 year. Additionally, data on sociodemographic status and menstrual and reproductive history were collected using a pretested questionnaire/schedule. Bivariate analyses (chi square test) revealed that significantly more number of caste participants suffered from urinary problems than their tribe counterpart. The reverse trend has been noticed for the frequency of vaginal problems. Multivariate analyses (binary logistic regression) show that sociodemographic variables and menstrual and reproductive history of the present study participants seem to be the concomitants of menopausal symptoms. Tribe and caste study population significantly differed with respect to the estrogen deficient menopausal problems and the concomitants to these problems.
\end{abstract}

\section{Introduction}

Menopause is associated with reduction in the normal estrogen levels and subsequent incidence of menopausal symptoms [1]. Studies stated that, during the early postmenopausal period, the prevalence of vasomotor symptoms ranges from 30 to 80 percent and, during later period, vaginal dryness from 25 to 47 percent [2]. The prevalence of urogenital complaints has been reported to increase at menopause and is more common in women than men, implicating menopause [3-5].

For most women, natural menopause takes place between the ages of 45 and 55 years [6,7]. In most developed countries, this event occurs around the age of 50 years [8]. But in developing countries like India there has been a trend in advancement of age at menopause [9]. Thus, along with increase in life expectancy growing number of these women can expect to live for several decades after menopause. Furthermore, several studies have shown that the frequency of reporting of menopausal symptoms of Indian women varies with culture and also with sociodemographic status $[10,11]$.

In Indian subcontinent, one may find an appreciable quantum of literature on menopause. To the best of the understanding of the authors, few studies addressed the menopausal issues of any indigenous ethnic group (tribe). Although in this globalised world we observe some radical change to have occurred in different societies, the indigenous ethnic group maintains homogeneity in the form of practicing endogamy and in maintaining traditional cultural beliefs. They differ from the other ethnic groups in terms of their biological and cultural identity such as mating structure and social tradition. This inequality in social and cultural characteristics is likely to affect the reproductive characteristics, including reproductive aging or menopause of the indigenous groups differentially.

Under this circumstance, the present study aims to find out the prevalence of menopausal problems between tribe and caste population of West Bengal, a state of east India. 


\section{Material and Methods}

2.1. Study Area. The present study has been conducted in one of the indigenous ethnic groups known as "Lodha" of West Bengal, a state located in eastern India. Lodha population have been declared as one of the "Particularly Vulnerable Tribal Groups" of this country on the basis of certain characteristics like low level of literacy, preagricultural level of technology, and declining or stagnant population. In West Bengal they mainly lived in the district of West Medinipur. We selected them from 5 villages of West Medinipur district. Caste population have been recruited from the same villages. Study areas have been selected using multistage random sampling techniques, considering one local administrative unit (gram panchayat) from the district and five villages from gram panchayat. Each of the administrative units was randomly selected.

2.2. Study Population. We identified 404 postmenopausal (221 Lodha and 183 caste participants) participants on the basis of the criteria fixed for the study: the participants were between the ages of 40 and 55 years, had attained natural menopause, were married, had at least one child, and had no history of hysterectomy or other major gynaecological problems. We have excluded childless participants from the study to ensure that all participants have been exposed to certain reproductive events/behaviour in life (like pregnancy, lactation, and parity) that modify the reproductive hormonal levels of participants. Finally 313 of these participants (172 Lodha and 141 caste participants) were available or volunteered to participate. Thus the total participation rate was $77.5 .9 \%$ (lodha $77.8 \%$ and schedule caste $77.0 \%$ ). The menopausal state was ascertained following the classification of the World Health Organization [8].

Prior to collection of data, the nature of research was explained and consent was taken from all the participants.

2.3. Data Types and Data Collection Techniques. A pretested and structured questionnaire was used to collect the data on sociodemographic status that include age of the participants at the time of interview, years of education, working status, per capita monthly household expenditure in Indian rupees, use of tobacco, and consumption of black tea or alcohol. Data on menstrual history includes ages at menarche, history of menstrual regularity, and history of heavy and scanty menstrual discharge; reproductive history includes age at marriage, use of oral contraceptive pills, number of live births, duration of breastfeeding (months), and history of sterilization. Barring the variable "age at menarche," information on other menstrual and reproductive factors pertains to the stage after the last child birth. Data collection techniques have been discussed elsewhere [12]. Menopausal problems of the participants were collected (last 30 days' recall) with the help of a "menopausal problem list" used in study on the Bengali speaking Hindu women of West Bengal [13]. The procedural details of using this questionnaire have been discussed elsewhere [13].

The present study is conducted during the period of March 2009 to July 2012. The study protocol has been approved by the "Research Ethics Committee" of the University of Calcutta, India (reference number: BEHR/1095/2304).

2.4. Methods of Analyses. We applied descriptive statistics (frequency and mean calculation) to compare the trend in the sociodemographic variables and menstrual and reproductive history and menopausal problems between tribe and caste postmenopausal participants. We also used $t$-test and $\chi^{2}$ test in bivariate comparisons.

Binary multivariate logistic regression (using enter method) analyses were done to find out the concomitants that significantly associated with menopausal problems. In these analyses, the presence or absence of menopausal problems were considered dependent variables. All the sociodemographic, menstrual, and reproductive variables were entered together in the analysis as independent variables. The following were the reference categories (in parenthesis) for each of the categorical variables: working status (nonworking), history of heavy or scanty menstrual discharge (absent), oral contraceptive pill (ever used), history of reproductive wastage (absent), sterilisation (absent), use of tobacco (no), and consumption of black tea (no). The rest of the variables, such as age of the participants at the time of interview, per capita monthly household expenditure, years of education, duration of breast feeding, and number of live births, were treated as continuous variables. The colinearity of the independent variables is checked and the values are found to be within the acceptable limit ( $\mathrm{SE}=0.001$ to 5.0 ). In the text, values of odds ratio and $95 \% \mathrm{CI}$ are presented only for those variables that showed significant association $(P \leq 0.05)$ with a particular menopausal problem. We excluded the variables like alcohol consumption from the multivariate analyses as none of the caste population and few sections of tribal women consume it.

\section{Results}

Table 1 shows that an overwhelming section of tribal participants had no formal education whereas more than half of the caste women got it. Larger section of caste participants belonged to nonworking category, but higher number of tribal participants were mostly engaged in day labour, small scale business, and agricultural activities. Per capita monthly household expenditure was significantly more in caste than in tribal participants. Significantly higher number of tribal participants were tobacco chewers and majority of participants consumed black tea. A few sections of tribal participants consume alcohol, but none of the caste ones consumes it. No significant differences have been observed between tribe and caste participants regarding mean age at menarche. An overwhelming section of participants had the history of menstrual regularity, whereas significantly higher number of tribal participants had the history of heavy and scanty menstrual discharge. Mean ages at marriage, first pregnancy, and last pregnancy and duration of breastfeeding were significantly earlier in tribal than caste participants. Mean number of live births was similar among both groups. Use of oral contraceptive and history of reproductive wastage 
TABLE 1: Socio demographic variables, menstrual and reproductive history.

\begin{tabular}{|c|c|c|c|}
\hline & Tribe $(n=172)$ & Caste $(n=141)$ & $P$ value \\
\hline Mean age of participants at the time of interview (years) & $49.09 \pm 4.7$ & $48.85 \pm 4.2$ & 0.052 \\
\hline Years of education & & & NA \\
\hline 0 & $163(94.6)$ & $66(46.8)$ & \\
\hline $1-4$ & $5(3.0)$ & $13(9.2)$ & \\
\hline $5-8$ & $3(1.8)$ & $37(26.2)$ & \\
\hline $9-10$ & $1(0.6)$ & $18(12.8)$ & \\
\hline$\geq 11$ & $0(0.0)$ & $7(5.0)$ & \\
\hline Working status & & & 0.097 \\
\hline Nonworking & $50(29.1)$ & $110(78.0)$ & \\
\hline Working & $122(70.9)$ & $31(22.0)$ & \\
\hline Mean per capita monthly household expenditure (in Indian rupees) & $998.35 \pm 22.2$ & $1080.96 \pm 27.8$ & 0.001 \\
\hline Use of tobacco (at least once in a week) & $122(70.9)$ & $28(19.9)$ & 0.001 \\
\hline Consumption of black tea (at least once in a week) & $145(84.3)$ & $120(85.1)$ & 0.844 \\
\hline Consumption of alcohol (at least once in a week) & $13(7.6)$ & $0(0.0)$ & NA \\
\hline Mean age at menarche (years) & $13.94 \pm 1.4$ & $14.10 \pm 1.6$ & 0.443 \\
\hline History of menstrual regularity & $169(98.3)$ & $335(98.2)$ & 0.990 \\
\hline Had periods with heavy discharge & $69(40.1)$ & $63(18.5)$ & 0.001 \\
\hline Had periods with scanty discharge & $47(27.3)$ & $30(8.8)$ & 0.001 \\
\hline Mean age at marriage (years) & $15.07 \pm 2.5$ & $17.29 \pm 3.4$ & 0.001 \\
\hline Mean age at first pregnancy (years) & $18.23 \pm 2.4$ & $20.05 \pm 3.1$ & 0.001 \\
\hline Mean age at last pregnancy (years) & $25.96 \pm 5.4$ & $27.21 \pm 4.8$ & 0.009 \\
\hline Mean number of live births & $3.70 \pm 1.77$ & $3.75 \pm 1.5$ & 0.738 \\
\hline Mean duration of breastfeeding of the last child (months) & $51.16 \pm 20.8$ & $37.81 \pm 32.2$ & 0.001 \\
\hline Ever use of oral contraceptive pills & $1(0.6)$ & $15(10.6)$ & 0.001 \\
\hline History of reproductive wastage & $12(7.0)$ & $29(20.5)$ & 0.004 \\
\hline History of sterilisation & $121(70.3)$ & $85(60.3)$ & 0.040 \\
\hline Mean age at menopause (years) & $41.69 \pm 5.6$ & $40.65 \pm 5.0$ & \\
\hline
\end{tabular}

Figures in the parentheses indicate percentage.

was significantly higher in caste than tribe participants, whereas significantly higher number of tribal participants have the history of sterilization. Tribal participants attained menopause at an earlier age than caste women.

Table 2 shows the frequency of menopausal symptoms of tribe and caste participants. Vasomotor problems like hot flush and night sweats did not differ significantly between tribe and caste participants. Urinary problems like inability to hold urine and urine leakage were significantly higher in caste participants than intribal ones. On the other hand, vaginal problems such as vaginal dryness, discharge, and bad smell were significantly higher among tribal than caste participants.

Table 3 shows that the chance of hot flush in tribal and caste participants increased with early age at menarche and early age at last pregnancy, respectively. The history of reproductive wastage increased the chance of night sweat among tribal participants. On the other hand the chance of this problem significantly increased in caste women with early onset of menarche, with history of scanty menstrual bleeding, and never use of oral contraceptive pills. Among the tribe, history of heavy menstrual discharge significantly increased the likelihood of the problem like painful urination but, among caste, late onset of menarche and age at marriage
TABLe 2: Prevalence of menopausal symptom types.

\begin{tabular}{lccc}
\hline & Tribe & Caste & $P$ value \\
\hline Vasomotor domain & & & \\
$\quad$ Hot flush & $66(38.4)$ & $57(40.4)$ & 0.400 \\
$\quad$ Night sweats & $94(54.7)$ & $76(53.9)$ & 0.492 \\
Urinary domain & & & \\
$\quad$ Painful urination & $44(25.6)$ & $25(17.7)$ & 0.062 \\
Inability to hold urine & $81(47.1)$ & $91(64.5)$ & 0.001 \\
Frequent urination & $50(29.1)$ & $54(38.3)$ & 0.054 \\
$\quad$ Urine leakage & $41(23.8)$ & $72(51.1)$ & 0.001 \\
Vaginal domain & & & \\
$\quad$ Vaginal dryness & $79(45.9)$ & $10(7.1)$ & 0.001 \\
Burning sensation & $16(9.3)$ & $7(5.0)$ & 0.105 \\
$\quad$ Vaginal discharge & $56(32.6)$ & $19(13.5)$ & 0.001 \\
Vaginal itching & $24(14.0)$ & $17(12.1)$ & 0.374 \\
$\quad$ Bad smell & $20(11.6)$ & $3(2.1)$ & 0.001 \\
\hline
\end{tabular}

Figures in the parentheses indicate percentage.

seemed to be the factors associated with this problem. Tribal participants who consume black tea and caste ones who use 


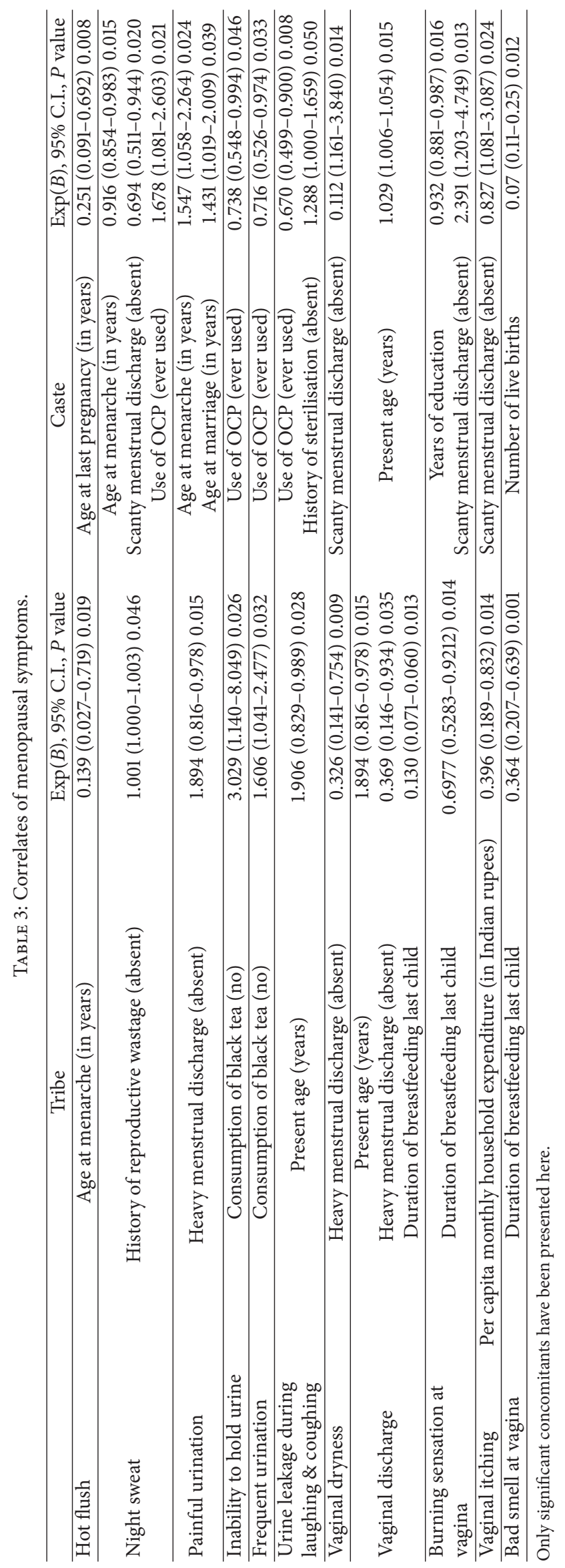


the oral contraceptive pills were more likely to be affected by inability to hold urine and frequent urination. Present age was a concomitant for urine leakage in tribal participants, whereas use of oral contraceptive pills and sterilization were found to be the concomitants for this problem for caste women. Presence of heavy and scanty type of menstrual discharge increased the chance of vaginal dryness in tribe and caste participants, respectively. In tribal participants present age, history of heavy menstrual discharge, and short duration of breastfeeding significantly increased the chance of vaginal discharge whereas present age was the only factor for caste participants. Concomitants like short duration of breastfeeding increased the chance of burning sensation of tribe; on the other hand fewer years of education and presence of scanty menstrual discharge significantly increased the likelihood of this problem in caste participants. Decrease in per capita monthly household expenditure and history of scanty menstrual discharge increased the chance of vaginal itching in tribe and caste participants, respectively, whereas decreased duration of breastfeeding and decreased number of live births significantly increased the likelihood of bad smell in vagina in tribe and caste participants, respectively.

\section{Discussion}

Menopause may have profound implications for subsequent morbidity and mortality [14]. Studies show that women who attain menopause at an early age are at a greater risk of being affected by cardiovascular disease [15], osteoporosis [16], and rheumatoid arthritis [17], while late menopause carries a higher risk of breast [18] and endometrial [19] cancer. The estrogen deficient menopausal problems lead to an increase in the progression of cytokines such as GM-CSF, IL-1, and IL6 , and that could potentially induce autoimmune responses in systemic autoimmune diseases such as SLE and rheumatoid arthritis [17, 20]. Aging is also associated with progressive decline in $\mathrm{T}$ cell functions, including decreased response to various antigens, and production of IL-2, and defect in signalling pathway resulting in the increase in frequency of cancer [21, 22].

Studies stated the relationship between hot flashes and certain reproductive history variables, such as age at menarche, age at first and last pregnancy, and parity; however it revealed the inconsistent result $[13,23,24]$. However, the present study showed that the likelihood of hot flush was more in the participants who attained menarche at an early age and had last pregnancy at their early age. Early onset of menarche might be associated with early exhaustion of ova [25] and early age at last pregnancy might be related with faster rate of atresia [26]. The ovarian shortage of oocytes for both reproductive events could formulate the fluctuation of oestrogen level during menopausal transition and occurrence of hot flush [27].

Consumption of black tea seemed to be the factor of urinary incontinences (inability to hold urine and frequent urination) of tribe participants whereas, along with the use of oral contraceptive pills, lower incidence of sterilization seemed to be the factor of urinary incontinences of caste ones.
In this context, it has been stated that the development of UI symptoms can also be affected by caffeine intake in the form of black tea. A study on women from USA reported that the incidence of UI was positively associated with caffeine ingestion, and a high level of intake increased the risk of urge but not stress or mixed incontinence [28]. Present study was corroborated with that finding. It has been found that caffeine has diuretic effect; thus intake of such substance can lead to rise in the pressure that is exerted inwards by the detrusor urinae muscles of the bladder wall, and this detrusor instability may produce urinary incontinence [29, 30]. Furthermore, earlier study stated that both the current and the former use of oral hormone therapy increased the risks of urinary incontinence (UI) among postmenopausal participants [31, 32]. Use of the hormone changed the collagen composition of the bladder and makes it contractile. Increased bladder contractility has been proposed as some potential explanations of the occurrence of UI [31, 32]. As OCP use was significantly more in caste study participants of this study compared to tribe ones, that might be a reason of more prevalence of urinary symptoms in caste participants.

Oestrogen is a dominant regulator of vaginal physiology. It has been found that oestrogen-receptor density is highest in the vagina [33-35]. Several features of the vaginal microenvironment change have been noticed with increasing age, mostly in response to alterations of oestrogen levels [35]. Present study was consistent with this finding. During menopause, the vaginal mucosa becomes weakened, loses its rugae, and appears pale and almost transparent because of decreased vascularity [36]. Present study showed that tribal study participants who had the history of heavy menstrual discharge and breastfeed their child for short time are more likely to be affected with the estrogen deficient symptoms like vaginal problems during her menopausal life. Whereas for a caste study participants, who had the history of scanty menstrual discharge and less number of live births, the chance of these types of problems increased. In this regard it has been said that short duration of breastfeeding and lower number of live births lead to the fast depletion of ovarian follicles [37]. As follicular decline results in lowered levels of oestrogen, faster exhaustion of ovarian follicle might be a reason of fluctuation of oestrogen that might be associated with occurrence of vaginal problems. Moreover, oestrogen deficiency was one of the reasons for heavy or scanty menstrual discharge [38]. So women who had the history of scanty menstrual discharge were more likely to suffer from vaginal symptoms during menopause [13].

Menopausal health of women is determined by their menstrual and reproductive histories, sociodemographic variable, and types of diet. They are susceptible to health problems by reason of either their genetics or their lifestyles and, finally, their access to adequate health care $[13,39$, 40]. Thus, inclusion of the data on dietary practices and genetics would give a better understanding of menopausal symptoms of the two different populations of the present study. Moreover, the findings of the present study suggest that variation exists in the menopausal experience and its socio demographic and reproductive concomitants between two ethnic groups living in the same geographical area. However, 
they are limited in generalizability due to the small sample size. Our volunteer sample may not be representative of the broader population of postmenopausal women from each of the ethnic groups.

\section{Conflict of Interests}

The authors declare that they have no competing interests.

\section{Acknowledgments}

The authors wish to thank the study participants for their valuable efforts and time and the University Grant Commission, India, for providing financial support.

\section{References}

[1] M. L. Traub and N. Santoro, "Reproductive aging and its consequences for general health," Annals of the New York Academy of Sciences, vol. 1204, pp. 179-187, 2010.

[2] L. Dennerstein, E. C. Dudley, J. L. Hopper, J. R. Guthrie, and H. G. Burger, "A prospective population-based study of menopausal symptoms," Obstetrics \& Gynecology, vol. 96, no. 3, pp. 351-358, 2000.

[3] D. E. Irwin, I. Milsom, S. Hunskaar et al., "Population-based survey of urinary incontinence, overactive bladder, and other lower urinary tract symptoms in five countries: results of the EPIC study," European Urology, vol. 50, no. 6, pp. 1306-1315, 2006.

[4] S. Correia, P. Dinis, F. Rolo, and N. Lunet, "Prevalence, treatment and known risk factors of urinary incontinence and overactive bladder in the non-institutionalized Portuguese population," International Urogynecology Journal, vol. 20, no. 12, pp. 1481-1489, 2009.

[5] A. Tinelli, A. Malvasi, S. Rahimi et al., "Age-related pelvic floor modifications and prolapse risk factors in postmenopausal women," Menopause, vol. 17, no. 1, pp. 204-212, 2010.

[6] M. Meschia, F. Pansini, A. B. Modena et al., "Determinants of age at menopause in Italy: results from a large cross-sectional study," Maturitas, vol. 34, no. 2, pp. 119-125, 2000.

[7] A. Biri, C. Bakar, I. Maral, O. Karabacak, and M. A. Bumin, "Women with and without menopause over age of 40 in Turkey: consequences and treatment options," Maturitas, vol. 50, no. 3, pp. 167-176, 2005.

[8] World Health Organization, "Research on the menopause in the 1990s. Report of a WHO scientific group," WHO Technical Report Series 866, World Health Organization, Geneva, Switzerland, 1996.

[9] Indian Institute of Population Sciences (IIPS) and ORC Macro, National Family and Health Survey-3, 2005-2006, IIPS, Mumbai, India, 2007.

[10] T. S. Syamala and M. Sivakami, "Menopause: an emerging issue in India," Economic and Political Weekly, vol. 40, pp. 4923-4930, 2005.

[11] V. Kakkar, D. Kaur, K. Chopra, A. Kaur, and I. P. Kaur, "Assessment of the variation in menopausal symptoms with age, education and working/non-working status in northIndian sub population using menopause rating scale (MRS)," Maturitas, vol. 57, no. 3, pp. 306-314, 2007.
[12] D. Dasgupta, B. Pal, and S. Ray, "Factors that discriminate age at menopause: a study of Bengali Hindu women of West Bengal," American Journal of Human Biology, 2015.

[13] D. Dasgupta and S. Ray, "Vasomotor and urogenital problems at midlife: a study on rural and urban women in India," Annals of Human Biology, vol. 42, no. 3, pp. 268-275, 2015.

[14] B. K. Jacobsen, I. Heuch, and G. Kvåle, "Age at natural menopause and all-cause mortality: a 37-year follow-up of 19,731 Norwegian women," American Journal of Epidemiology, vol. 157, no. 10, pp. 923-929, 2003.

[15] Y. T. Schouw, Y. Graaf, E. W. Steyerberg, M. J. C. Eijkemans, and J. D. Banga, "Age at menopause as a risk factor for cardiovascular mortality," The Lancet, vol. 347, no. 9003, pp. 714-718, 1996.

[16] D. Kritz-Silverstein and E. Barrett-Connor, "Early menopause, number of reproductive years, and bone mineral density in postmenopausal women," American Journal of Public Health, vol. 83, no. 7, pp. 983-988, 1993.

[17] D. Deon, S. Ahmed, K. Tai et al., "Cross-talk between IL-1 and IL-6 signaling pathways in rheumatoid arthritis synovial fibroblasts," The Journal of Immunology, vol. 167, no. 9, pp. 53955403, 2001.

[18] D. Trichopoulos, B. MacMahon, and P. Cole, "Menopause and breast cancer risk," The Journal of the National Cancer Institute, vol. 48, no. 3, pp. 605-613, 1972.

[19] A. Kalandidi, A. Tzonou, L. Lipworth, I. Gamatsi, D. Filippa, and D. Trichopoulos, "A case-control study of endometrial cancer in relation to reproductive, somatometric, and life-style variables," Oncology, vol. 53, no. 5, pp. 354-359, 1996.

[20] M. Feldmann, F. M. Brennan, and R. N. Maini, "Role of cytokines in rheumatoid arthritis," Annual Review of Immunology, vol. 14, pp. 397-440, 1996.

[21] S. Gupta, R. Bi, K. Su, L. Yel, S. Chiplunkar, and S. Gollapudi, "Characterization of naïve, memory and effector CD8+ T cells: effect of age," Experimental Gerontology, vol. 39, no. 4, pp. 545$550,2004$.

[22] J.-N. Cao, S. Gollapudi, E. H. Sharman, Z. Jia, and S. Gupta, "Age-related alterations of gene expression patterns in human CD8 ${ }^{+}$T cells," Aging Cell, vol. 9, no. 1, pp. 19-31, 2010.

[23] K. Ford, M. Sowers, M. Crutchfield, A. Wilson, and M. Jannausch, "A longitudinal study of the predictors of prevalence and severity of symptoms commonly associated with menopause," Menopause, vol. 12, no. 3, pp. 308-317, 2005.

[24] S. Sabia, A. Fournier, S. Mesrine, M.-C. Boutron-Ruault, and F. Clavel-Chapelon, "Risk factors for onset of menopausal symptoms: results from a large cohort study," Maturitas, vol. 60, no. 2, pp. 108-121, 2008.

[25] F. Parazzini, "Determinants of age at menopause in women attending menopause clinics in Italy," Maturitas, vol. 56, no. 3, pp. 280-287, 2007.

[26] D. W. Cramer, H. Xu, and B. L. Harlow, "Does 'incessant' ovulation increase risk for early menopause?" American Journal of Obstetrics \& Gynecology, vol. 172, no. 2, pp. 568-573, 1995.

[27] D. C. Deecher and K. Dorries, "Understanding the pathophysiology of vasomotor symptoms (hot flushes and night sweats) that occur in perimenopause, menopause, and postmenopause life stages," Archives of Women's Mental Health, vol. 10, no. 6, pp. 247-257, 2007.

[28] Y. H. Jura, M. K. Townsend, G. C. Curhan, N. M. Resnick, and F. Grodstein, "Caffeine intake, and the risk of stress, urgency and mixed urinary incontinence," The Journal of Urology, vol. 185, no. 5, pp. 1775-1780, 2011. 
[29] S. M. Creighton and S. L. Stanton, "Caffeine: does it affect your bladder?” British Journal of Urology, vol. 66, no. 6, pp. 613-614, 1990.

[30] R. J. Maughan and J. Griffin, "Caffeine ingestion and fluid balance: a review," Journal of Human Nutrition and Dietetics, vol. 16, no. 6, pp. 411-420, 2003.

[31] F. Grodstein, K. Lifford, N. M. Resnick, and G. C. Curhan, "Postmenopausal hormone therapy and risk of developing urinary incontinence," Obstetrics \& Gynecology, vol. 103, no. 2, pp. 254-260, 2004.

[32] S. L. Hendrix, B. B. Cochrane, I. E. Nygaard et al., "Effects of estrogen with and without progestin on urinary incontinence," Journal of the American Medical Association, vol. 293, no. 8, pp. 935-948, 2005.

[33] M. B. Hodgins, R. C. Spike, R. M. Mackie, and A. B. MacLean, "An immunohistochemical study of androgen, oestrogen and progesterone receptors in the vulva and vagina," British Journal of Obstetrics and Gynaecology, vol. 105, no. 2, pp. 216-222, 1998.

[34] G. D. Chen, R. H. Oliver, B. S. Leung, L.-Y. Lin, and J. Yeh, "Estrogen receptor alpha and beta expression in the vaginal walls and uterosacral ligaments of premenopausal and postmenopausal women," Fertility and Sterility, vol. 71, no. 6, pp. 1099-1102, 1999.

[35] J. B. Gebhart, D. J. Rickard, T. J. Barrett et al., "Expression of estrogen receptor isoforms alpha and beta messenger RNA in vaginal tissue of premenopausal and postmenopausal women," American Journal of Obstetrics and Gynecology, vol. 185, no. 6, pp. 1325-1331, 2001.

[36] S. L. Hofland and J. Powers, "Sexual dysfunction in the menopausal woman: hormonal causes and management issues," Geriatric Nursing, vol. 17, no. 4, pp. 161-165, 1996.

[37] J. Ginsburg, "What determines the age at the menopause? The number of ovarian follicles seems the most important factor," British Medical Journal, vol. 302, no. 6788, pp. 1288-1289, 1991.

[38] B. L. Sweeney, K. Dennis, and A. Desai, "Gynecologic and obstetric disorders: contraception, hormone replacement therapy and endometriosis," in Gibaldi's Drug Delivery Systems in Pharmaceutical Care, M. Lee and A. Desai, Eds., pp. 321-344, American Society of Health-System Pharmacists, Bethesda, Md, USA, 2007.

[39] Pan American Health Organization (PAHO), Midlife and Older Women in Latin America and the Caribbean, Pan American Health Organization, Washington, DC, USA, 1989.

[40] C. Bernis and D. S. Reher, "Environmental contexts of menopause in Spain: comparative results from recent research," Menopause, vol. 14, no. 4, pp. 777-787, 2007. 


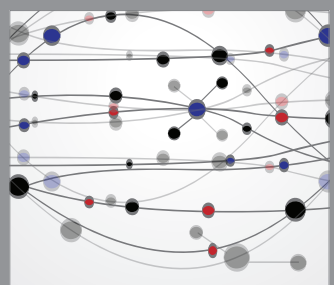

The Scientific World Journal
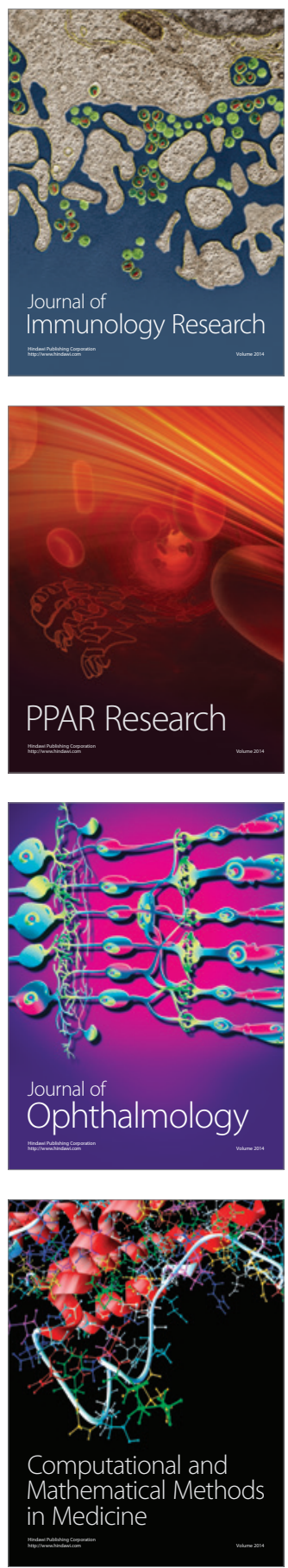

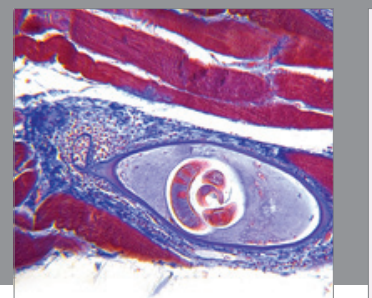

Gastroenterology

Research and Practice
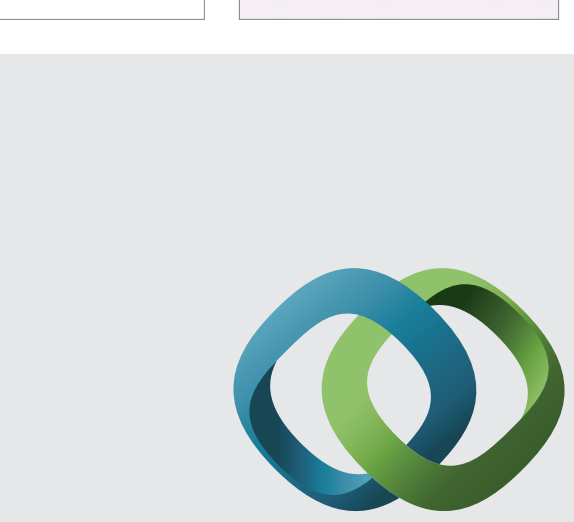

\section{Hindawi}

Submit your manuscripts at

http://www.hindawi.com
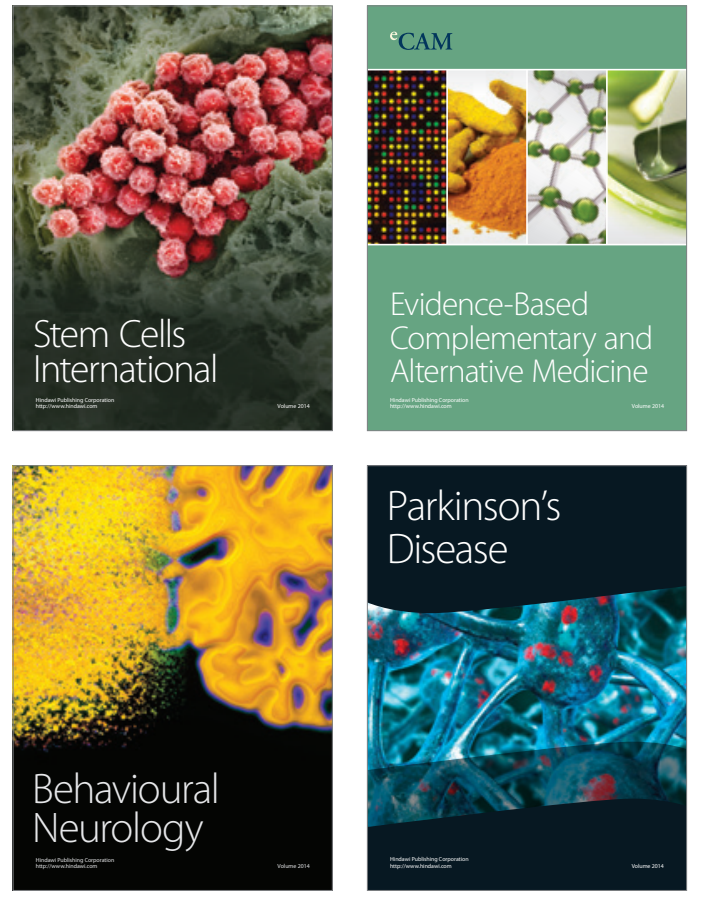
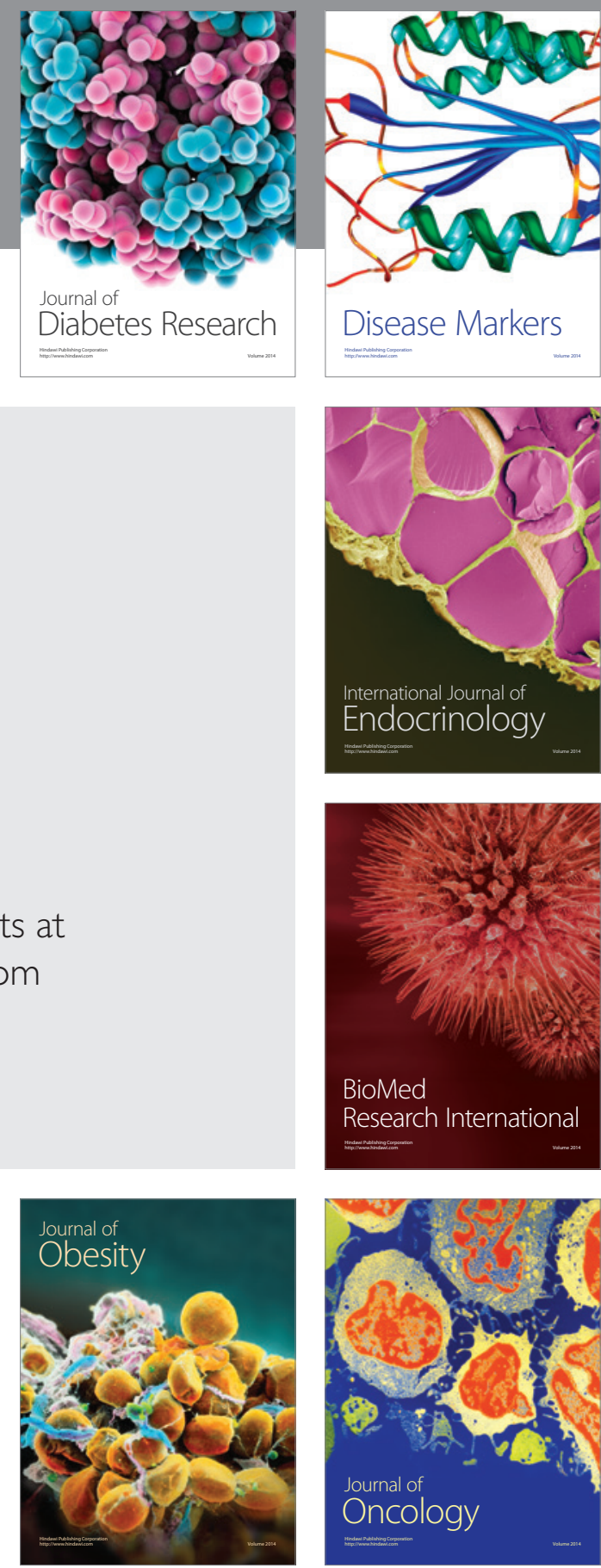

Disease Markers
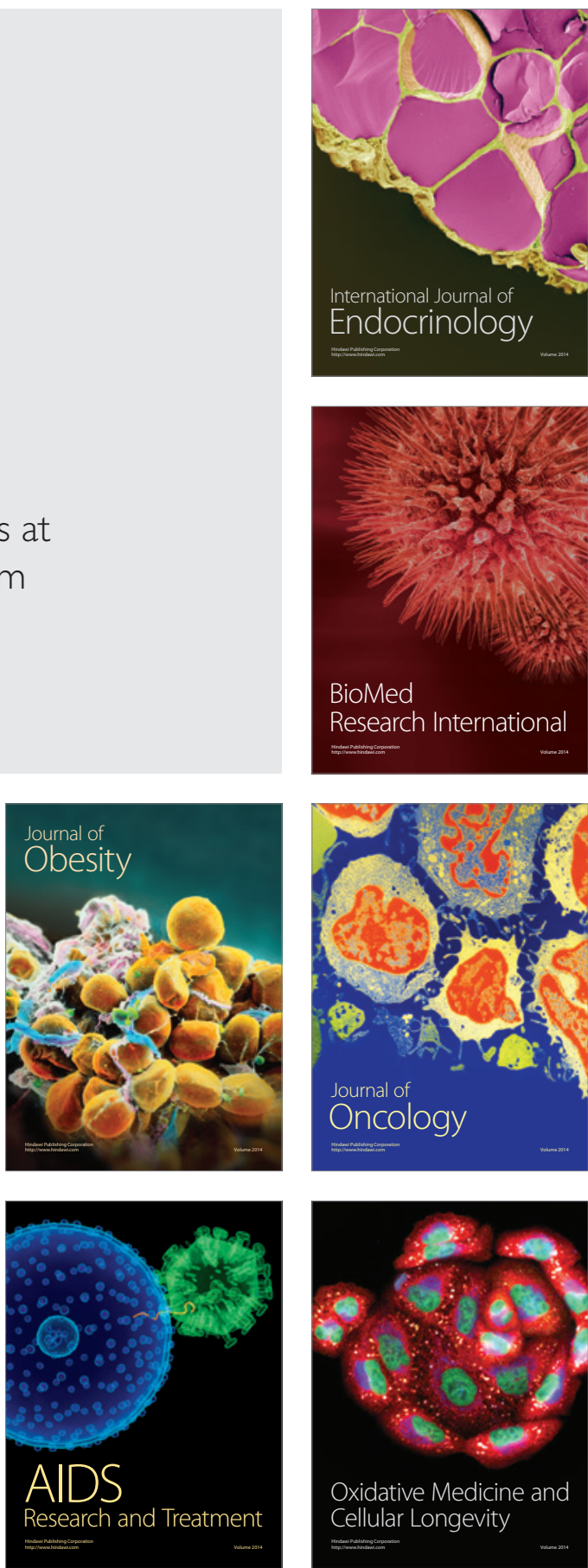